\title{
Physical workload during firefighting in Chilean volunteers
}

\author{
Javier A. Freire Herrera ${ }^{\text {a, }}$, Felipe E. Meyer Cohen ${ }^{a}$ and Elías S. Apud Simón ${ }^{\text {a }}$ \\ ${ }^{a}$ Unit of Ergonomics, Faculty of Biological Sciences, University of Concepcion, Edmundo Larenas s/n, Concep- \\ cion, Chile
}

\begin{abstract}
The study was performed in a sample of 39 firemen. The state of health for each fire fighter was evaluated by means of a clinical examination and also through some specific exams. Aerobic capacity was estimated as an indicator of physical fitness. In each load, cardiac frequency and oxygen consumption were measured under a steady state condition. Additionally, body composition was calculated using a Tanita professional scale. Physical effort at work was determined by measuring cardiac frequency using a telemetric unit. Evaluations were carried out during night shifts, registering information under the following conditions: night shifts without emergency, fire simulation, training exercises and real fire fighting. In general terms, it is possible to state that fire fighters are healthy according to the result of the clinical examination. However, it is very important to highlight that $70 \%$ of the firemen consume alcohol and $80 \%$ were smokers. The average aerobic capacity of the sample was $2.61 / \mathrm{min}$ or $34.5 \mathrm{ml} / \mathrm{kg} / \mathrm{min}$. In terms of overweight and obesity, the body mass index was 25.7 , whereas the percentage fat mass reached an average of $22.9 \%$. The cardiovascular load in the night shifts without emergencies did not surpass $40 \%$, which in Chile is considered the highest limit for sustained work. However, during training, simulations and real fires, the firemen had higher cardiac frequencies, reaching peak levels close to $100 \%$ cardiovascular load.
\end{abstract}

Keywords: aerobic capacity, fire fighters, cardiovascular load

\section{Introduction}

\subsection{Physical conditions of firemen volunteers}

A Chilean fireman fighter works voluntarily, without renumeration. This fact indicates that the majority also hold other jobs, which could eventually be an additional factor of physical or mental fatigue. It is necessary to mention that in order to join any fire department in Chile, one must meet certain requirements. Among them are being over 18 and under 40 years old, and being in adequate health. In the case of firefighting, there exist some activities that are at the very limit of physical and psychological capacities, a product of environmental conditions and organizational difficulties, due to the unpredictable magnitude of these tasks.

The knowledge of this reality forces us to take effective measures, with the objective of avoiding fati- gue in volunteers and increasing safety in the activities that they perform. In that sense, a study carried *

out by the National Association of the Protection against Fires between 1977 and 1995 shows that close to $50 \%$ of all deaths that occurred during fire emergencies were not directly the result of firefighting, but instead were due to heart attacks. It is emphasized that their deaths were caused directly by the high demands of the job.

\subsection{Physical demands of fire fighting}

Fighting fires is a difficult job and physically hard. According to Womack (2000) [6], the energy demands of fire extinguishing activities, during the initial minutes, reach about $40 \mathrm{ml} / \mathrm{kg} / \mathrm{min}$ of oxygen consumption, with a heart rate of about 180 heart beats/minute and a pulmonary ventilation close to 130 liters of air per minute.

* Javier Freire, Casilla 160-C, correo-3 Concepción, Chile. Email: javierfreire@udec.cl. Tel.:56-041-2204426; Fax: 56-0412522045. 
On the other hand, Davis (1982) [4], after monitoring 100 professional firemen, concluded that maximum heart rate reached 169 heart beats per minute, which was equivalent to $91 \%$ of the maximum heart rate of the group. Post studies, such as those of Lusa (1993), Davies (1995) and Bilzon et al. (2001) [3], are in agreement as to the high levels of heart rate and energy expenditure experienced by the firemen. The aims of the present study were:

- To identify, evaluate and propose interventions to reduce the risk factors of firefighting.

- On the basis of the requirements of fire fighting, to analyse if the group of evaluated firemen have the necessary physical condition to carry out this dangerous work without fatigue.

\section{Methodology and materials}

In the present study, 39 volunteers from the Hualpén Fire Department, in Chile, participated. In the first stage, an obesity indicator evaluation was carried out in which the body mass index (BMI) was used. In addition, body composition was estimated through impedance on a TANITA scale.

Aerobic capacity was estimated using the technique of extrapolation, according to Maritz et al (1961) [5]. For this purpose, the subjects exercised at three workloads on a mechanically braked bicycle ergometer (Monark, Sweden). $\mathrm{VO}_{2}$ was measured using an open circuit method, Apud et al. [1]. Measurements of cardiac frequency and $\mathrm{VO}_{2}$ were recorded once a steady state had been reached for each load.

Subsequently, and based on the results of the previous evaluation, the support of the city hall was accomplished through the Center of Family Health, which provided a complete evaluation of the health condition of the volunteers. These evaluations comprised a preventive medical exam, blood tests, a visual acuity test, audiometry, spirometry and an electrocardiogram.
The physical demands to which the volunteers are exposed to are evaluated through heart rate telemetry, with a POLAR system (RS 400) during night shifts, training exercises and real emergency situations. In table 1 , the details of the evaluations performed on the firemen in these situations are displayed.

Table 1

Evaluation of the cardiovascular load in different firemen activities.

\begin{tabular}{|c|c|c|}
\hline Evaluation & $\begin{array}{l}\text { Evaluated } \\
\text { Firemen }\end{array}$ & Total Evaluations \\
\hline $\begin{array}{l}\text { Shifts without } \\
\text { emergencies }\end{array}$ & $\begin{array}{l}4 \text { to } 5 \text { per } \\
\text { shift }\end{array}$ & 150 evaluations \\
\hline Fire drill & 8 firemen & 8 evaluations \\
\hline $\begin{array}{l}\text { Regular } \\
\text { training }\end{array}$ & 8 firemen & 8 evaluations \\
\hline Real fire & 4 firemen & evaluations \\
\hline
\end{tabular}

\section{Results and discussion}

Based on obesity indicators, it is necessary to highlight (table 2) that the average of body mass index was 25.7 with a minimum of 17.7 and a maximum of 31.9 . In relation to body mass percentage, the average is $22.9 \%$, which expressed in kilograms is 18.2 kilos average. According to the health condition, it is worth mentioning that the medical exam revealed that $70 \%$ of the evaluated volunteers consume alcohol and $80 \%$ consume tobacco. In relation to the blood tests, these were found in normal levels with some exceptions such as a particular case which reached a value of $649 \mathrm{mg} / \mathrm{dl}$ of triglycerides. The same normal situation was found in the results, audiometries, spyrometries, visual acuity tests and electrocardiograms.

The average aerobic capacity in the volunteers was $2.61 / \mathrm{min}$, which is equivalent to $34.5 \mathrm{ml} / \mathrm{kg} / \mathrm{min}$ with a minimum of 15.6 and a maximum of $60 \mathrm{ml} / \mathrm{kg} / \mathrm{min}$, as observed in table 2 . In figure 1 , the distribution of the aerobic capacity values in $1 / \mathrm{min}$ are displayed. 
Table 2

Basic physical characteristics of 39 Chilean fire fighters

\begin{tabular}{|l|l|l|l|l|l|}
\hline Variable & Unit & $\begin{array}{l}\text { Mean } \\
\text { Value }\end{array}$ & Min & Max & St. Dev. \\
\hline Age & $\mathrm{yr}$ & 29.2 & 17.0 & 54.0 & 8.4 \\
\hline Weight & $\mathrm{kg}$ & 77.3 & 53.4 & 99.7 & 11.3 \\
\hline Height & $\mathrm{cm}$ & 173.5 & 159.0 & 196.0 & 8.9 \\
\hline BMI & & 25.7 & 17.7 & 31.9 & 3.7 \\
\hline Fat mass & $\%$ & 23.5 & 7.9 & 49.9 & 8.1 \\
\hline Fat mass & $\mathrm{kg}$ & 18.7 & 4.9 & 49.5 & 8.5 \\
\hline Aerobic Capacity & $1 / \mathrm{min}$ & 2.7 & 1.4 & 5.3 & 0.7 \\
\hline Aerobic Capacity & $\mathrm{ml} / \mathrm{kg} / \mathrm{min}$ & 34.5 & 15.6 & 60.0 & 9.1 \\
\hline
\end{tabular}

Figure 1.

Distribution of aerobic capacity $(1 / \mathrm{min})$.

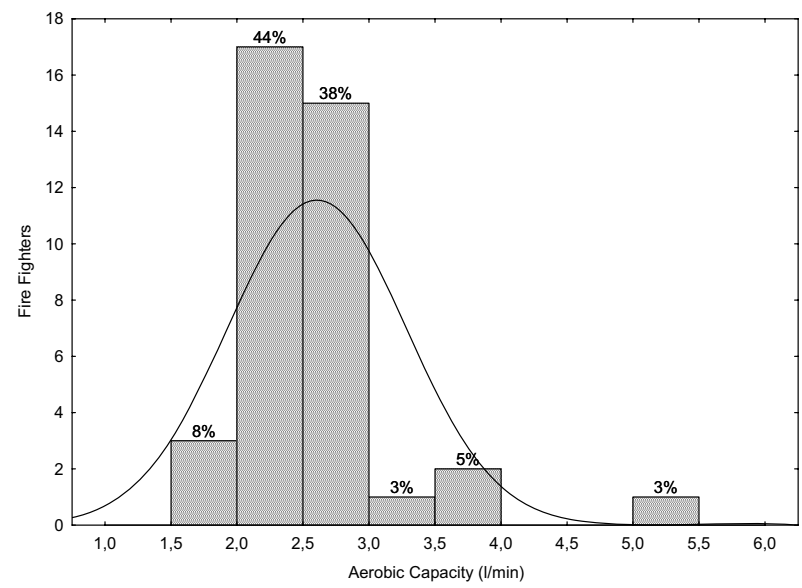

Based on the results of the cardiovascular load, it was observed that during night shifts without any sort of emergency, the volunteers did not exceed in any case $40 \%$ of aerobic capacity, finding themselves on average between 10 to $20 \%$. For example, in figure 2, the heart rate variations of a volunteer during a night shift without emergencies are displayed.

The measurement of cardiovascular load during a physical training session that includes going up and down stairs, pulling and coiling hoses, crawling, and striking with a mallet, in a determined cycle, revealed that the evaluated volunteers exceeded levels of $40 \%$ of cardiovascular load, even reaching peak levels in a range between 80 and $100 \%$, as shown in the example of a volunteer illustrated in figure 3 .
Figure. 2.

Heart rate of a volunteer during a night shift without emergencies.

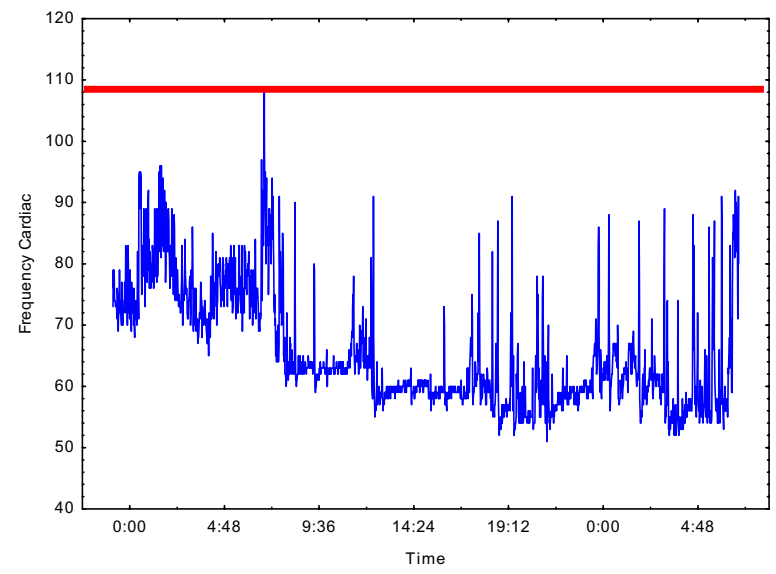

Figure 3.

Heart rate of a volunteer during the field exercise of consumption

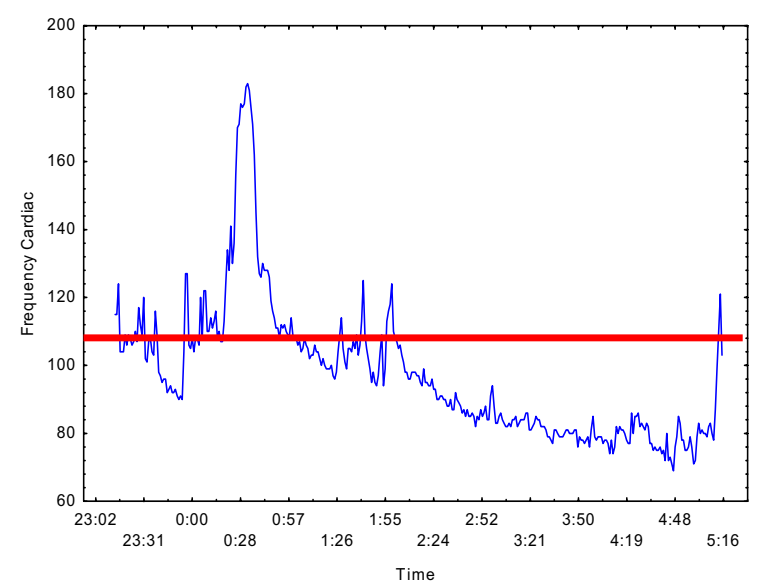


As to the fire drills, which the volunteers faced without previous notifications during a night shift, cardiovascular loads were registered which exceeded $80 \%$ during the course of the activity. As an example, in figure 4 , variations in the heart rate of a volunteer who participated in a fire drill at 00:10hrs, and subsequently had to attend a real fire at 03:30, are shown. It is interesting to observe in the figure that the intensity of the efforts, according to the heart rate, was very similar.

Figure 4 .

Graphics of the heart rate of a volunteer during the fire drill and later in his activity during a real fire

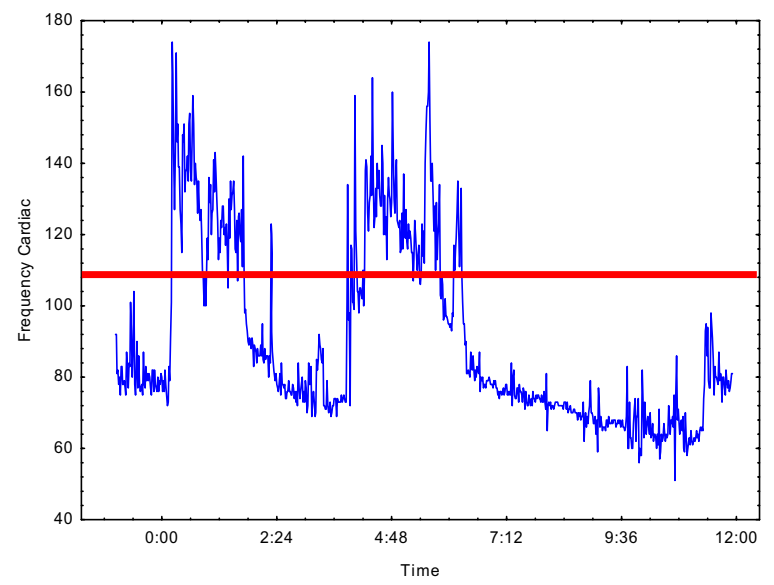

\section{Conclusions and discussion}

The indicators of obesity of the firefighter volunteers from Hualpén indicate that $61.6 \%$ are overweight or have different degrees of obesity.

The aerobic capacity of the vast majority of the fire fighters is low, highlighting that $79.5 \%$ possess a level inferior to the standard that has been shown in previous studies undertaken in forest fire departments, Apud et (2002) [2].

Based on the demands of the activities, it can be stressed that during all of the evaluations of cardiovascular loads, on $90 \%$ of the working days emergencies were not registered and as it was highlighted in the results, during these periods, this load did not exceed $40 \%$. In contrast to these results, in the performed activities, that is, training exercises, fire drills and real fires, a common factor was the high cardiovascular load that the volunteers are subjected to. This could be explained in part by poor physical preparation and the job demands, which are practically impossible to diminish.

To summarize, the firefighter volunteers are found under the minimum levels of selection proposed for the fire departments in Chile, which have been developed considering the physical demands that firefighting imposes. These standards are displayed in table 3 , where it is highlighted that $85.7 \%$ have a lower than adivisable aerobic capacity $(\mathrm{ml} / \mathrm{kg} / \mathrm{min})$ and $88.6 \%$ have a body mass percentage above that which is advisable for young people performing these duties.

The results of this study reveal the urgent necessity of improving the physical condition of firefighters. For these purposes, a physical conditioning program was recommended with the aim of modifying conditions such as obesity and bad habits like smoking. A training program was suggested which was designed by a physical education teacher who considered the current condition of the volunteers, established times of reevaluation in order to analyze the changes in conditions induced by the regular exercise, performed at least three times a week. The design considered aerobic activities and muscular strengthening.

On the other hand, it was also proposed to incorporate selection criteria of the volunteers, setting some physical requirements for their entrance. There criteria were:

1. Aerobic capacity superior to 40 $\mathrm{ml} /$ kgrs/weight.

2. Percentage of fat mass under $20 \%$ of body mass.

3. Normal audiometry.

4. Normal vision.

5. Not presenting relevant obstructive pathologies according to spyrometry.

6. Normal electrocardiogram.

These indicators that are important for entrance cannot be taken rigidly, since there are factors that can be improved with training and proper diet. Furthermore, fire fighters must be regularly controlled over time, taking into account that over the years, physical aptitude tends to diminish. Nonetheless, it is also necessary to consider that this decrease can be very well compensated for by the experience that people acquire while they execute these tasks. 


\section{References}

[1] Apud, E., Meyer, F.’Ergonomía para la industria minera". University of Concepcion, Chile. (2009).

[2] Apud, E., Meyer, F. and Maureira, F. "Ergonomía en el combate de incendios forestales". Valverde, University of Concepcion, Chile. (2002).

[3] Bilzon J, Allsop A, Tipton M (2001). Assessment of physical fitness for occupations encompassing load-carriage tasks. Occ Med., 51.5, 357-361.

[4] Davis P, Dotson C, Santa Maria D. Relationship between simulated fire-fighting tasks and physical performance measures, Med Sci Sport and Exercise, (1982),14, pp 67-71.

[5] Maritz, J.S., Morrison, J.F., Peter, J., Strydom, N.B. and Wyndham, C.H. "A practical method of estimating individual's maximal oxygen uptake". Ergonomics. 4: 97, 1961.

[6] Womack, J.W., Green, J.S., Crouse, S.F. Cardiovascular Risk Markers in Fire Fighters: A Longitudinal Study. Cardiovascular Reviews and Reports 21. (2000). (10): pp 544-548. 